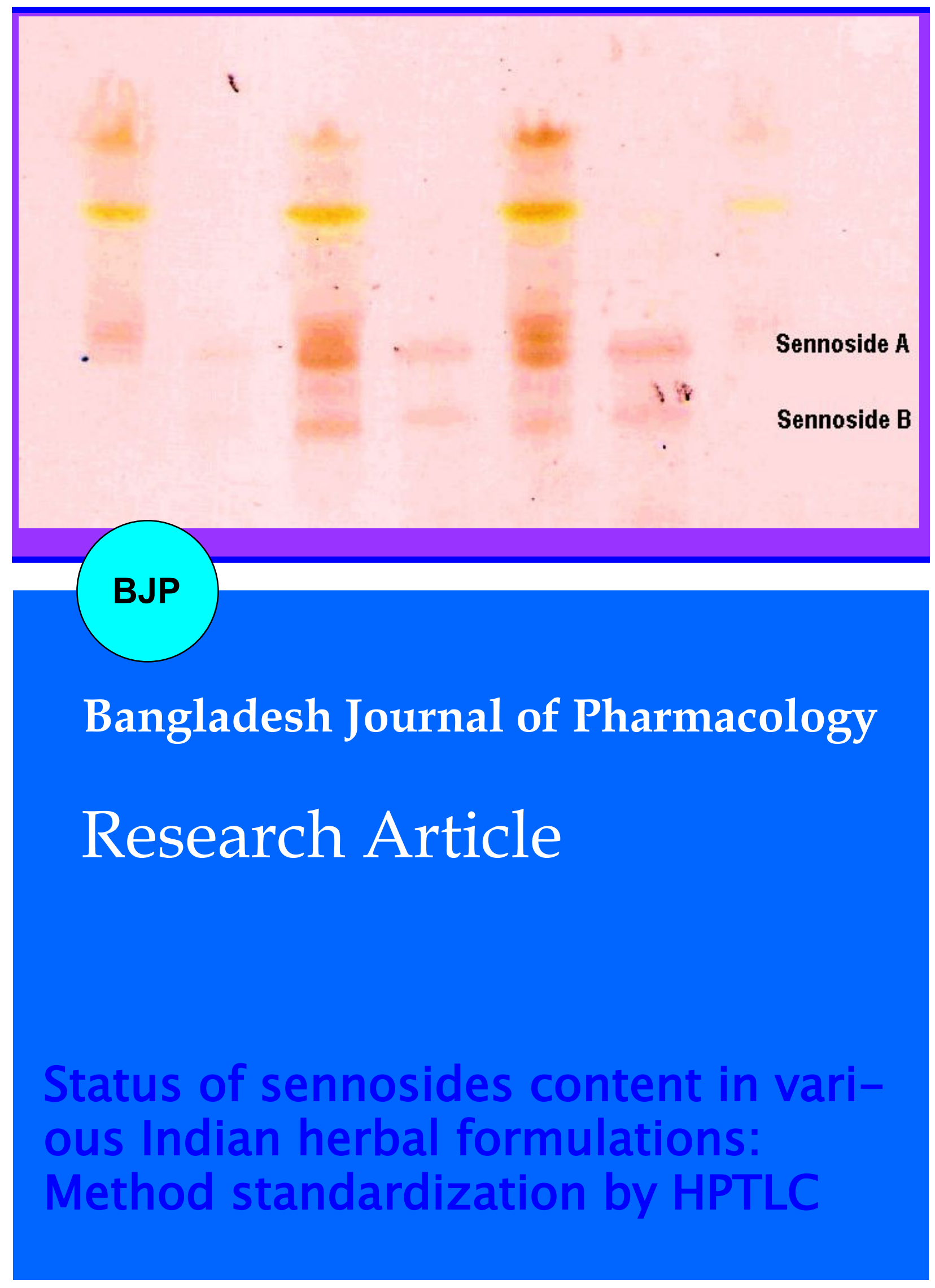




\title{
Status of sennosides content in various Indian herbal formulations: Method standardization by HPTLC
}

\author{
Md. Wasim Aktar, Rajlakshmi Poi and Anjan Bhattacharyya
}

Regional Analytical Laboratory for Medicinal and Aromatic Plants, Department of Agricultural Chemicals, Bidhan Chandra Krishi Viswavidyalaya, Mohanpur 741252, Nadia, West Bengal, India.

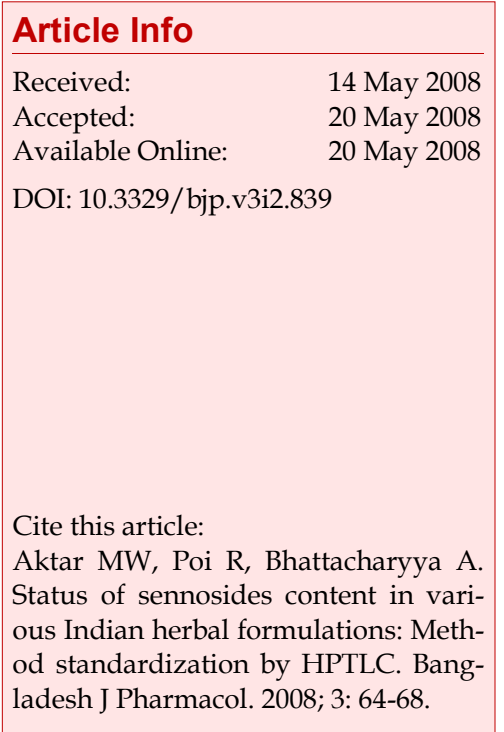

\begin{abstract}
Several polyherbal formulations containing senna (Cassia angustifolia) leaves are available in the Indian market for the treatment of constipation. The purgative effect of senna is due to the presence of two unique hydroxy anthracene glycosides sennosides A and B. A HPTLC method for the quantitative analysis of sennosides $\mathrm{A}$ and $\mathrm{B}$ present in the formulation has been developed. Methanol extract of the formulations was analyzed on a silica gel $60 \mathrm{GF}_{254}$ HPTLC plates with spot visualization under UV and scanning at $350 \mathrm{~nm}$ in absorption/reflection mode. Calibration curves were found to be linear in the range $200-1,000 \mathrm{ng}$. The correlation coefficients were found to be 0.991 for sennoside A and 0.997 for sennoside B. The average recovery rate was $95 \%$ for sennoside A and $97 \%$ for sennoside B showing the reliability and reproducibility of the method. Limit of detection and quantification were determined as 0.05 and $0.25 \mu \mathrm{g} / \mathrm{g}$ respectively. The validity of the method with respect to analysis was confirmed by comparing the UV spectra of the herbal formulations with that of the standard within the same $R_{f}$ window. The analysis revealed a significant variation in sennosides content.
\end{abstract}

\section{Introduction}

Cassia angustifolia (Family: Caesalpiniaceae), popularly known as senna, is a valuable plant drug in ayurvedic and modern system of medicine for the treatment of constipation (Atal et al., 1982; Das et al., 2003; Martindale, 1977; Sharma, 2004). Sennoside A and B are the two anthraquinone glycosides that are responsible for purgative action of senna. A variety of poly-herbal formulations containing senna leaves are available in India to relief constipation and allied troubles. Senna is a strong purgative that should be taken in proper dosage otherwise it may lead to gripping and colon problem (Bhattacharjee, 2004). Different analytical techniques, viz, thin layer chromatography, spectrophotometry, column chromatography have been reported in the literature for estimation of sennosides (Azam et al., 2002; Bala et al., 2000; Habib et al., 1980; Lin et al., 1998). HPTLC method has also been reported (Shah et al., 2000). But these techniques are tedious and time consuming. The present paper reports a simple, rapid and accurate HPTLC method for analysis of sennoside A and B occurring in herbal formulations and to make an assessment on the status of sennoside $\mathrm{A}$ and $\mathrm{B}$ content in the laxative formulations.

\section{Materials and Methods}

Ten different branded herbal formulations (polyherbal, 
powdered/microgranules) were collected from herbal shops of local markets.

Analytical standards of sennoside A and B were obtained from M/s. ChromaDex, Santa Ana, CA, USA. Solvents (methanol, 2-propanol, ethyl acetate, formic acid) used in entire study were from Merck, India.

\section{Preparation of standard solutions}

Standard solutions of sennoside A and sennoside B (1 $\mathrm{mg} / 5 \mathrm{~mL}$ ) were prepared in methanol.

\section{Extraction of samples}

Each $4 \mathrm{~g}$ of different branded formulation was sonnicated with $70 \%$ methanol $(3 \times 20 \mathrm{~mL})$ for about 45 min. Then the extract was filtered in a Buchner funnel using Whatman No. 1 filter paper and was concentrated under vacuum in a rotary evaporator at $50^{\circ} \mathrm{C}$, redissolved in methanol and finally reconstituted in 20 $\mathrm{mL}$ methanol prior to HPTLC analysis.

\section{Chromatographic parameters}

Chromatography was performed on glass-backed silica gel $60 \mathrm{GF}_{254} \mathrm{HPTLC}$ layers $(20 \times 20 \mathrm{~cm}$; $0.3 \mathrm{~mm}$ layer thickness) prepared using a Camag TLC plate auto coater (Camag, Switzerland). Samples and standard compounds 1 and 2 of known concentrations were applied as $8 \mathrm{~mm}$ wide bands using Camag Linomat 5 automated TLC applicator (Camag, Multenz, Switzerland) with nitrogen flow providing delivery speed $150 \mathrm{~nL} / \mathrm{sec}$ from the syringe. These parameters were kept constant through out the analysis.

\section{Detection and quantification of sennosides}

After completion of sample application, the plate was developed in a Camag Twin through glass tank presaturated with mobile phase of 2-propanol: ethyl acetate: water: formic acid (17:19:12:2.) for one hour. The TLC runs were performed under laboratory conditions of $25 \pm 2{ }^{\circ} \mathrm{C}$ and $60 \%$ relative humidity. After development the plates were taken off and dried by drier. Sennosides A and B were quantified using a Camag TLC Scanner model 3 equipped with Camag Wincats software applying the following conditions: slit width $6 \times 0.5 \mathrm{~mm}$, wavelength $\left(\lambda_{\max }\right) 350 \mathrm{~nm}$, absorption -reflection scan mode. The identification of sennosides $\mathrm{A}$ and $\mathrm{B}$ in formulations was confirmed by superimposing the UV spectra of samples and standards within the same $R_{\mathrm{f}}$ window.

\section{Validation of HPTLC method}

The linearity of the method was evaluated by analyzing a series of standard solutions. Eight different concentrations of standard solutions (each volume repeated twice) containing sennosides A and B were analyzed by HPTLC exactly as described above and the standard calibration curves were obtained by plotting the concentration of standard solutions versus peak area. The amount of sennosides A and B present in the formulations were determined by means of calibration curve. To study the accuracy and precision of the method, recovery studies were performed by addition of standard solutions $0.1,0.5$ and $1 \mu \mathrm{g}$ per gram of the formulations and the quantitative analysis was repeated thrice. Peak purity test of sennoside A and B were done by comparing UV spectra of sennoside A and $B$ respectively in standard and sample tracks. Peak purity results (obtained by scanning at $350 \mathrm{~nm}$ ) were satisfactory.

\section{Results and Discussion}

Figure 1 shows the distinct separate bands of sennoside $\mathrm{A}$ and $\mathrm{B}$ by TLC. The high resolution and reproducible peaks were obtained (Figure 2) by using the mobile phase 2-propanol: ethyl acetate: water: formic acid (17:19:12:2). The wavelength $350 \mathrm{~nm}$ was found to give the highest sensitivity. Linearity of sennoside A and B was found in the concentration range 200-1000 ng. Regression analysis of the experimental data points showed a linear relationship with excellent correlation coefficient ( $\mathrm{r}$ ) of sennoside A and sennoside B of 0.991 and 0.997 , respectively (Table I). The average recovery rate was $95 \%$ for sennoside A and $97 \%$ for sennoside B (Table II) showing the reliability and reproducibility of the method. In this study the limit of detection (LOD) and limit of quantification of sennoside A and B were determined to be 0.05 and $0.25 \mathrm{mg} / \mathrm{g}$.

The result (Table III) showed that the relative amount of sennoside A and B in formulation-1 was highest and in formulation-10 it was lowest. The result reflected a 2.8 times higher concentration in formulation-1 compared to that of formulation-10. The minimum content of sennoside B (considering the highest content as 100\%) was shown only by $5.4 \%$ in case of formulation- 10 and less than $17.5 \%$ in case of formulation number ' 3 ' to ' 9 '. This result clearly revealed that there is a significant variation of sennoside A and B content in popular herbal formulations. Since the chemical contents are biologically active, variation in their daily dose may impact on health benefits. Therefore, it is necessary that herbal formulations should always be analyzed to 


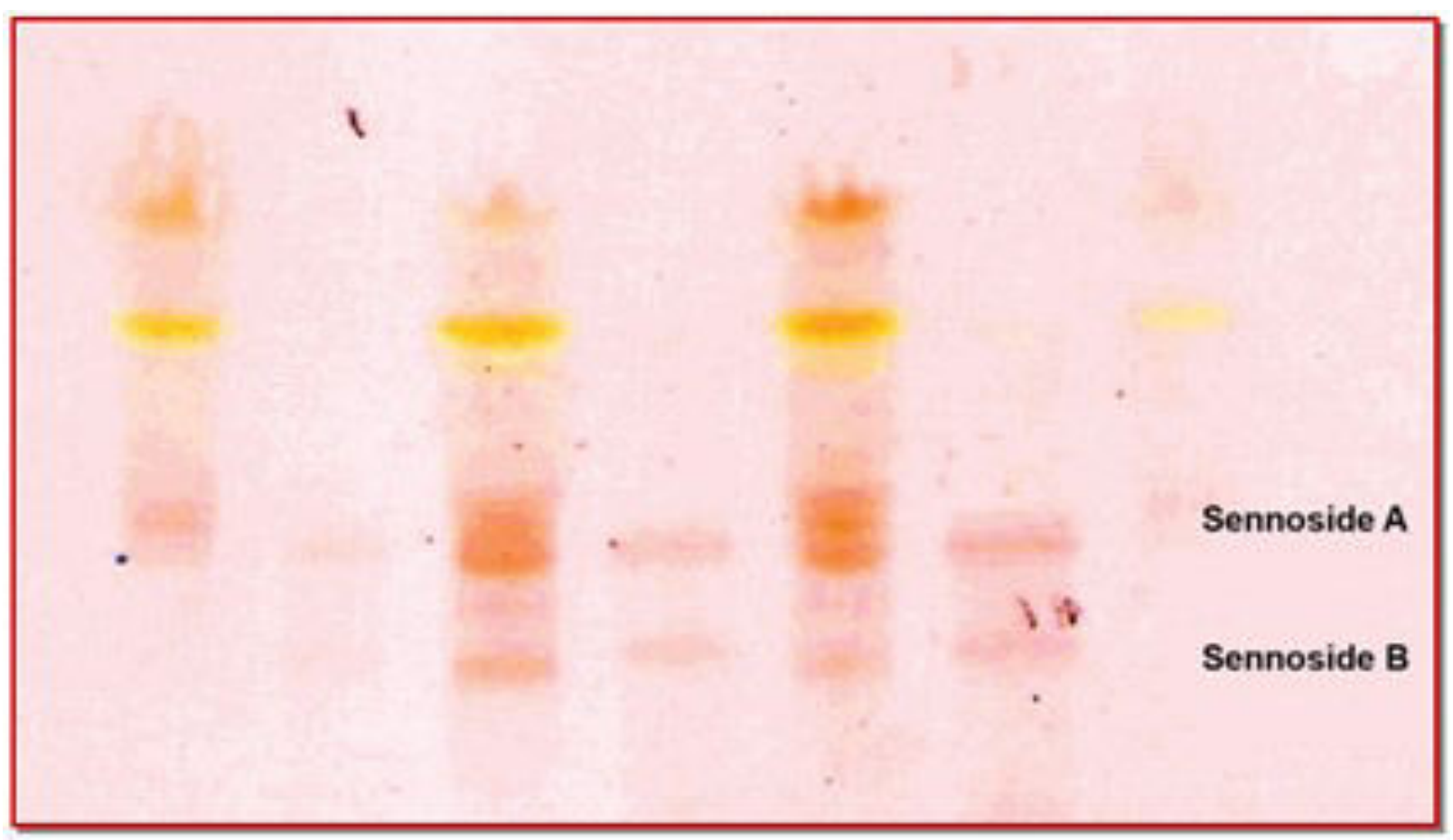

Figure 1: TLC plate showing the distinct separation of sennoside A and B after development in Twin Trough chamber

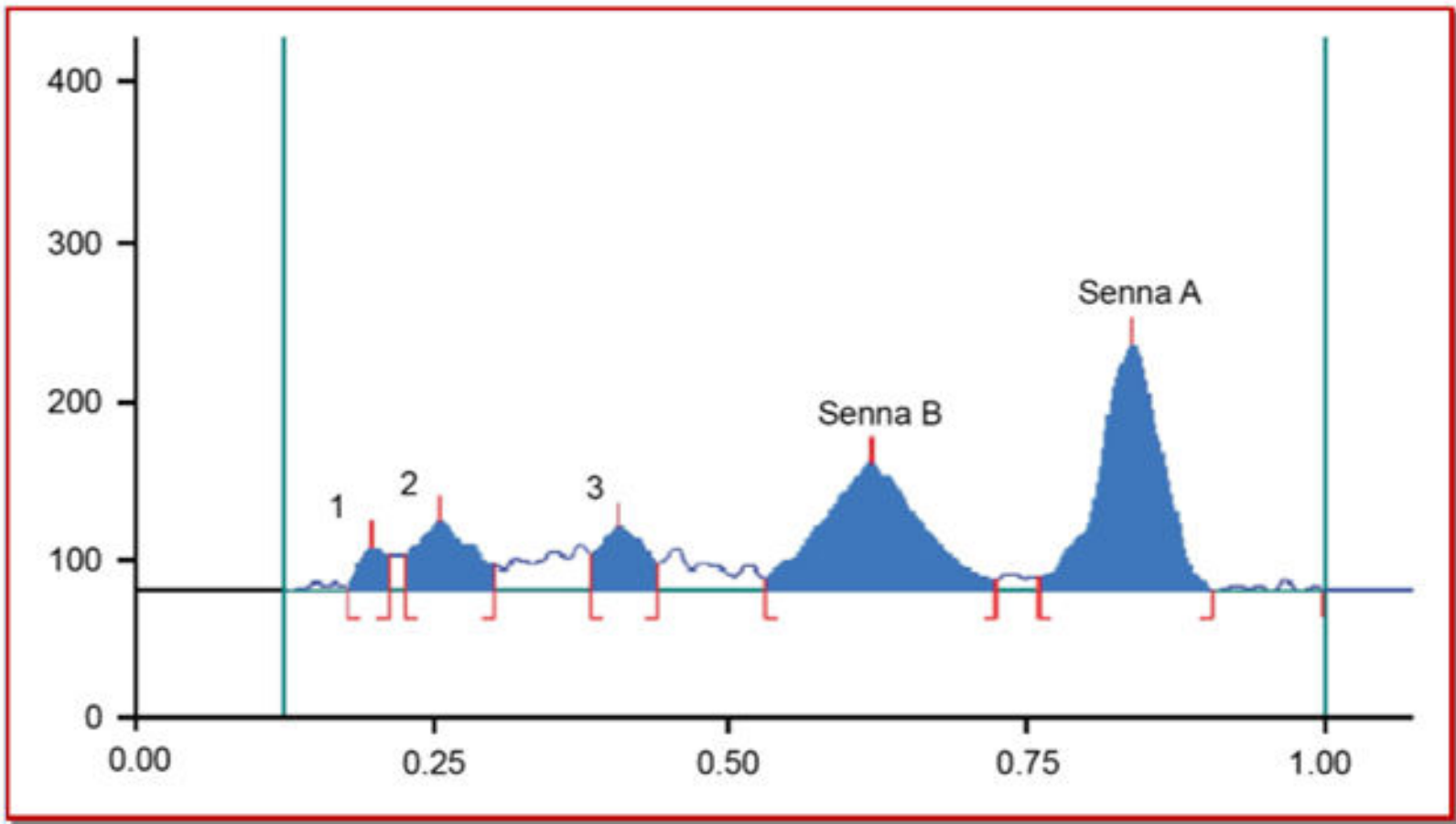

Figure 2: Scan (at $350 \mathrm{~nm}$ ) showing the separation of sennoside A and B in the extract of a laxative formulation 
Table I

$\mathbf{R}_{\mathrm{f}}$ values by HPTLC and linear regression equation for the determination of sennoside A and B

\begin{tabular}{lccc} 
Compound & Rf value & Regression equation & $\mathrm{r}$ \\
\hline Sennoside A & 0.84 & $\mathrm{Y}=7.087 \mathrm{X}+107.744$ & 0.991 \\
Sennoside B & 0.63 & $\mathrm{Y}=3.589 \mathrm{X}+702.086$ & 0.997
\end{tabular}

commercial formulations for quality evaluation. Method is very simple, rapid and suitable for rapid screening of plant materials for genotypic assessment and can be performed without any special sample pretreatment. The method is less expensive than an LC method. The method is, thus, suitable for quality control laboratories, where economical use of time and space is essential.

\begin{tabular}{|lcccccc|}
\hline \multicolumn{9}{c|}{ Table II } \\
\hline
\end{tabular}

Table III

\begin{tabular}{|l|c|c|}
\hline \multicolumn{1}{|c|}{ Sennoside A and B in selected herbal formulations } \\
\hline $\begin{array}{c}\text { Herbal formu- } \\
\text { lations }\end{array}$ & $\begin{array}{c}\text { Sennoside A } \\
\text { (mg/g of formula- } \\
\text { tion) }\end{array}$ & $\begin{array}{c}\text { Sennoside B } \\
\text { (mg/g of for- } \\
\text { mulation) }\end{array}$ \\
\hline Formulation-1 & 2.5 & 25.9 \\
\hline Formulation-2 & 2.3 & 12.7 \\
\hline Formulation-3 & 2.1 & 2.6 \\
\hline Formulation-4 & 1.8 & 1.9 \\
\hline Formulation-5 & 1.6 & 1.9 \\
\hline Formulation-6 & 1.6 & 1.7 \\
\hline Formulation-7 & 1.4 & 4.5 \\
\hline Formulation-8 & 1.2 & 1.5 \\
\hline Formulation-9 & 0.9 & 1.5 \\
\hline Formulation-10 & 0.9 & 1.4 \\
\hline
\end{tabular}

maintain the quality of the herbs present inthe formulation.

\section{Conclusion}

The proposed HPTLC method can be used for the determination of sennoside $A$ and $B$ in various

\section{Financial Support}

Ministry of Agriculture, Government of India, NMPB, Government of India and FPI \& H, Government of West Bengal

\section{Ethical Issue}

The study was approved by the Ethical Committee of the Bidhan Chandra Krishi Viswavidyalaya

\section{Conflict of Interest}

Authors declare no conflict of interest

\section{References}

Atal CK, Kapoor BM. Cultivation and utilization of medicinal plants. Jammu Twai, India, RRL, 1982, p 8.

Azam MM, Limy T. An improved HPLC method for estimation of sennosides in senna. Indian J Pharm Sci. 2002; 64: 178-81.

Bala S, Uniyal GC, Dubey T, Singh SP. An improved method for the analysis of sennosides in Cassia angustifolia by HPLC presented on national seminars on frontiers of research and development in medicinal plants. Lucknow, CIMAP, 2000.

Bhattacharjee SK. A handbook of medicinal plant. Jaipur, 
India, Pointer Publisher, 2004, pp 74-79.

Das PN, Purohit SS, Sharma AK, Kumar T. A handbook of medicinal plants. Jodhpur, India, Agrobios, 2003, p 118.

Evans FJ, Lee MG, Games DE. Electron impact, chemical ionization and field desorption mass spectra of some anthraquinone and anthrone derivatives of plant origin. Biol Mass Spectrometry. 1979; 6: 374-80.

Habib AA, EI-Sebakhy NA. Spectrophotometric estimation of sennosides and rhein glycosides in senna and its preparations. J Nat Prod. 1980; 43: 452-58.

Khafagy SM, Girgis AN, Khayyal SE, Helmi MA. Estimation of sennosides A, B, C and D in senna leaves, pods and formulation. Planta Med. 1972; 21: 304-09.

Lin YT, Huang CY. Determination of sennoside A and B in Diet tea by HPLC. J Fd Drug Anal. 1998; 6: 433-38.

Martindale. The extra pharmacopoeia. 27th ed. London, The Pharmaceutical Press, 1977, pp 1342-43.

Shah SA, Ravisankara MN, Nirmal A, Shishoo CJ, Rathod IS, Suhagia BN. Estimation of individual sennosides in plant material and marketed formulations by an HPTLC method. J Pharm Pharmocol. 2000; 52: 445-49.

Sharma R. Agro-techniques of medicinal plants. Delhi, Daya Publishing House, 2004, pp 176-77. 